\title{
Independent-exposure Method in Electron-beam Lithography
}

\author{
Do-Kyun Woo and Sun-Kyu Lee \\ Gwangiu Institute of Science and Technology \\ Republic of Korea
}

\section{Introduction}

Lithography technologies can be distinguished by mask lithography and scanning lithography so-called direct-writing process. The representative for mask lithography is photo-lithography, while the representative for scanning lithography is electron-beam lithography. Electron-beam lithography as scanning lithography has three major processing in the lithography procedure: (1) resist deposition, (2) alignment \& exposure and (3) development.

Electron-beam lithography is one of the most important fabrication technologies for the topdown miniaturization and high-accuracy 2D and 3D surface profile because the wavelength of electron-beam calculated by De Broglie's wavelength is much shorter than that of the source of other lithography (Sinzinger \& Johns, 2003; Kley, E.B \& Schnabel, B. 1995; Hirai et al., 2000).

In the photo-lithography, there is the limitation of pattern resolution by optical diffraction, but electron beam lithography does not have the limitation of pattern resolution by diffraction due to the much shorter wavelength. Compared to photo-lithography, electronbeam lithography has some attractive advantages including: (1) small spot size under 10nm, (2) no mask, (3) the precise control of electron beam by electrostatic or magnetic lens, (4) lower defect densities (Madou, 2002).

However, electron beam lithography also has some disadvantages including: (1) strong scattering of electrons in solid affecting the increase of pattern resolution, (2) high cost of system and maintenance, (3) more complex machine system than photo-lithography system due to the requirement of vacuum and electron optics (Madou, 2002).

For the fabrication of micro optical elements such as a multi-level lens and a binary structure in electron beam lithography, it was suggested that the alignment method should be used. It consists of a sequence of binary scanning pattern with $L$ step which results in $N=2^{L}$ number of level (Dammann, 1970; Goodman \& Silvestri, 1970; Kong, et al., 2004; Woo et al., 2009).

Fig. 1 shows the alignment method for the fabrication of a 4-level lens in which $L$ step is 2 . Thus, there are 2 times of repetitive processes between electron beam lithography and etching process. In addition, alignment marks and technology in this method have to be required in order to reduce the fabrication error. Thus, it is also important to design and fabricate the alignment structure. Due to the sequence of binary fabrication step and repetitive process, it requires more time and cost for the fabrication of such a multi-level lens. 

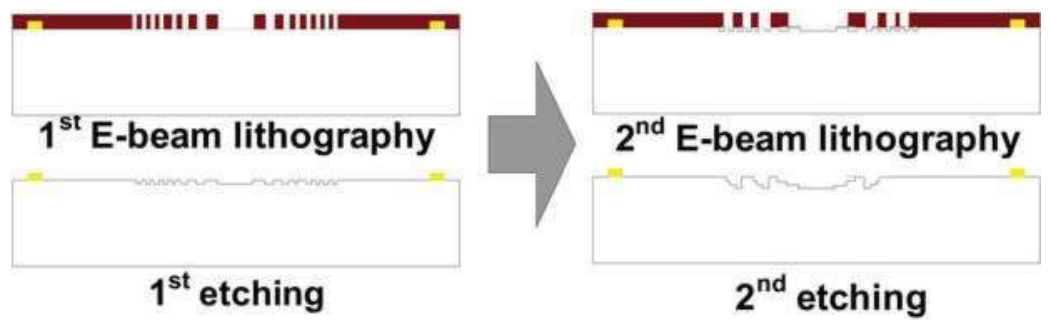

Fig. 1.alignment method for the fabrication of a 4-level lens

However, the independent-exposure method suggested in this chapter can reduce such a fabrication processes, which results in reduction of fabrication time and cost. We will discuss the fundamentals of the new fabrication technique in electron-beam lithography called Independent-exposure method which can be available for the structure of planar substrates with the reduction of the fabrication time and cost.

\section{Independent-exposure method}

\subsection{Principle}

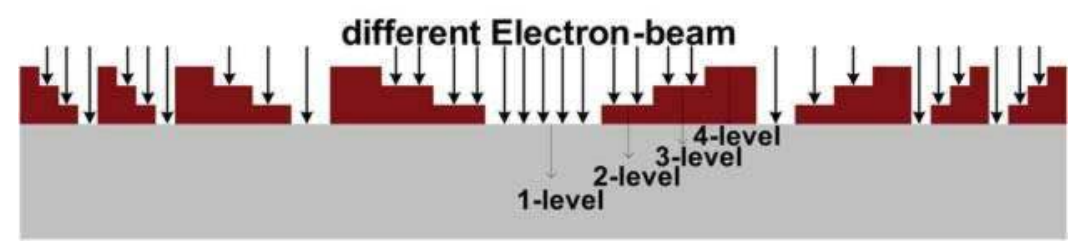

Fig. 2. Schematic of Independent-exposure method (Woo et al., 2008)

It was known that the electron beam resist thickness can be controlled by the modulation of exposure dose in electron beam lithography (Hirai et al., 2000). Based on this, the principle of independent-exposure method for the fabrication of a multi-level lens is to make the resist profile identical to that of a multi-level lens by different and appropriate electron beam dose (Woo, et al. 2008). Fig. 2 shows the schematic of independent-exposure method for a 4-level lens in electron beam lithography. After the independent-exposure lithography, we can obtain the mould of the 4-level lens through a Fast Atom Beam (FAB) plasma etching process with a 1:1 etching ratio of resist and substrate. Thus, the independent-exposure method for the fabrication of a multi-level lens or binary structure consisting of precise patterns has the major advantage of non-repetitive fabrication process between electron beam lithography and etching. The ultimate goal of this approach is to reduce the fabrication time and expense.

In this method, however, the developed resist thickness is not linearly proportional to the amount of electron beam dose due to the proximity effect which results from scattered electrons. When the electrons interact with the resist and substrate, the electrons can be scattered; the former is called "forward scattering", and the latter is called "backward scattering". The proximity effect is created by both forward and backward scattering. Due to the proximity effect, the area of the resist which is not intended can be partially exposed by these scattered electrons. Thus, the proximity effect in the electron beam lithography affects the increase of pattern resolution as well as the developed resist thickness (Chang, 1975). 
In order to fabricate such a multi-level lens or binary structure using the independentexposure method, we have to keep two crucial considerations in mind: (1) The resist thickness should be greater than that of a multi-level lens we designed because of 1:1 etching ratio in etching process, (2) the relation between the electron beam dose and the thickness of developed resist should be definitely clarified (Woo et al. 2008)

\subsection{Spin coating}

In order to obtain the exactly designed pattern through electron beam lithography, it is also important for the resist to be uniformly deposited on substrate. The spin coating for the deposition of resist with uniform thickness has been considered as the general way. In the spin coating, there are three important parameters to uniformly deposit resist: (1) the enough highly spin speed, (2) the viscosity of the coated resist, and (3) the clean substrate.

If the spin speed is low, the thickness of electron beam resist is not uniform as that shown in Fig. 3 (a) and if the substrate and circumstance is not clean, resist can not be uniformly deposited as that shown in Fig. 3 (b).

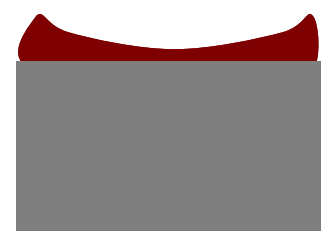

(a)

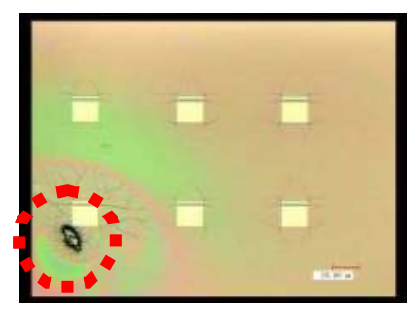

(b)

Fig. 3. factors on non-uniform thickness of resist: (a) low spin speed, (b) Impurity of substrate and circumstance

Because the relation of spin speed and the deposited thickness for each resist is not same, the company producing electron beam resist will provide the data sheet about the relation between the resist thickness and spin coating speed. In this work, we used the ZEP 520A as the positive electron beam resist by ZEON Corporation. It has high resolution, high sensitivity and dry etching resistance. Fig. 4 shows the relation between spin speed and the thickness of deposited resist in the technical report provided by ZEON Corporation (ZEON, 2003). Thus we can uniformly control the thickness of deposited resist with spin coating based on the spin speed curve.

As early mentioned, the independent-exposure method requires that the thickness of electron beam resist be more than that of a designed multi-level lens. In general, the thickness of a multi-level lens is in range of $600 \mathrm{~nm}$ and $1200 \mathrm{~nm}$. However, the thickest thickness of ZEP520A resist with 2000rpm as the lowest spin speed shown in Fig. 4 is approximately $500 \mathrm{~nm}$, which is less than that of a multi-level lens.

In this chapter, the way to deposit ZEP520A as electron beam resist with the thickness over $1000 \mathrm{~nm}$ will be described. It was not simply possible to deposit ZEP520A with the thickness over $1000 \mathrm{~nm}$ by twice consecutive spin coatings of 2000rpm because the resist in second spin coating cannot easily adhere to the resist deposited in the first spin coating.

However, we could obtain the resist layer satisfying the uniform thickness of approximately $1100 \mathrm{~nm}$ by inserting an accelerant which is able to improve the adhesion of electron beam resist and substrate. In this work, we used the OAP (Tokyo Ohka Kogyo Co., LTD) as an 


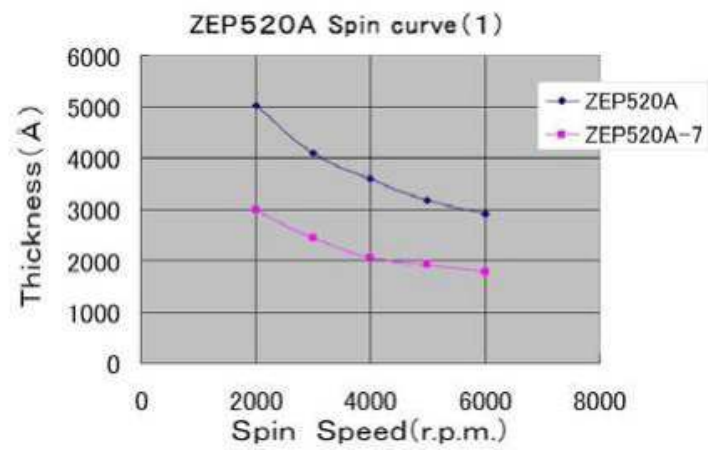

Fig. 4. ZEP520A Spin curve in technical report by ZEON corporation (ZEON, 2003)

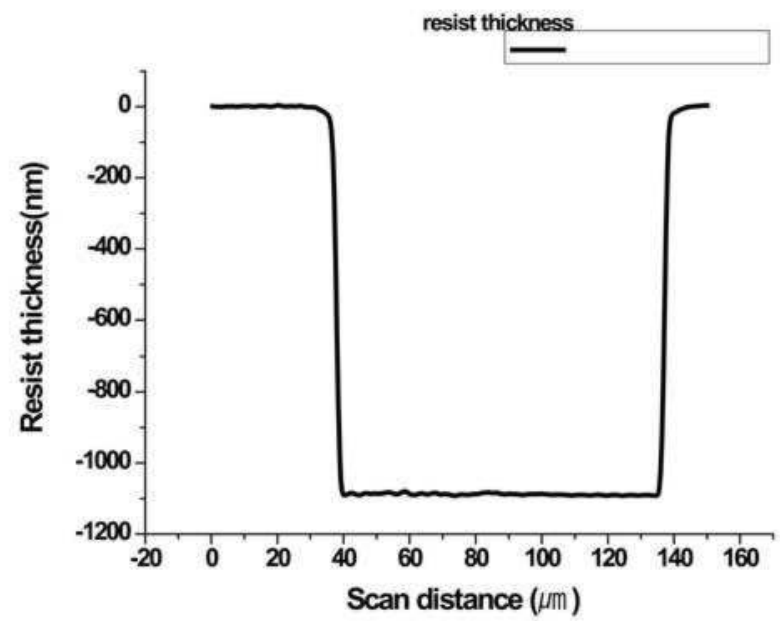

Fig. 5. Resist thickness with twice spin coatings of 2000rpm

accelerant. It is verified through repetitious experiments with the same condition that the range of the thickness of deposited resist is from 1070nm to $1140 \mathrm{~nm}$ as shown in Fig. 5 . Compared to the thickness of a multi-level lens, it is adequate to make an experiment with such a deposited resist for the fabrication of a multi-level lens by the independent-exposure method. Table 1 represents the conditions of the spin coating for the deposition of resist with a thickness of approximately 1100nm.

\begin{tabular}{|l|l|l|l|}
\hline 1. pre-baking & $180^{\circ} \mathrm{C}(3 \mathrm{~min})$ & 4. OAP spin coating & $\begin{array}{l}1200 \mathrm{rpm}(5 \mathrm{~s}) \\
+3000 \mathrm{rpm}(30 \mathrm{~s})\end{array}$ \\
\hline $\begin{array}{l}\text { 2. ZEP 520A spin } \\
\text { coating }\end{array}$ & $\begin{array}{l}500 \mathrm{rpm}(3 \mathrm{~s}) \\
+2000 \mathrm{rpm}(60 \mathrm{~s})\end{array}$ & $\begin{array}{l}\text { 5. ZEP-520A spin } \\
\text { coating }\end{array}$ & $\begin{array}{l}500 \mathrm{rpm}(3 \mathrm{~s}) \\
+2000 \mathrm{rpm}(60 \mathrm{~s})\end{array}$ \\
\hline 3. Soft baking & $180^{\circ} \mathrm{C}(3 \mathrm{~min})$ & 6. Soft baking & $180^{\circ} \mathrm{C}(3 \mathrm{~min})$ \\
\hline
\end{tabular}

Table 1. The conditions of the spin coating for independent-exposure method 


\subsection{Relation between electron beam dose and resist}

Before fabricating a multi-level lens by independent-exposure method, we should have another important preliminary experiment about relation between electron beam dose and the developed resist because the thickness of developed resist can be controlled by the modulation of electrons. In addition, it is better for us to certify whether there is another relation between resist and electron beam dose or not. To do this, we used two patterns with a different width of $10 \mu \mathrm{m}$ and $80 \mu \mathrm{m}$ as shown in Fig. 6 under the experiment conditions in table 2. In this experiment, we controlled the electron beam dose from $30 \mu \mathrm{C} / \mathrm{cm}^{2}$ to $100 \mu \mathrm{C} / \mathrm{cm}^{2}$ with a step of $10 \mu \mathrm{C} / \mathrm{cm}^{2}$ (Woo et al., 2008)

\begin{tabular}{|l|l|}
\hline Pattern width $(\mu \mathrm{m})$ & $10 \mu \mathrm{m}, 80 \mu \mathrm{m}$ \\
\hline Electron beam dose $\left(\mu \mathrm{C} / \mathrm{cm}^{2}\right)$ & $30,40,50,60,70,80,90,100$ \\
\hline
\end{tabular}

Table 2. Experiment conditions for relation between the exposure dose and the developed resist thickness (Woo et al., 2008).

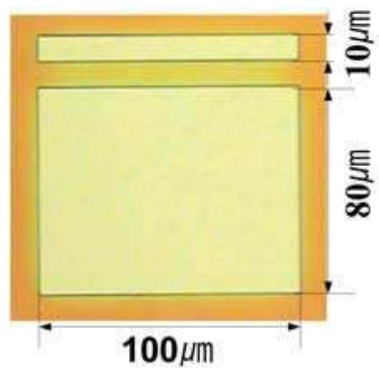

Fig. 6. Patterns for the experiment about the relation between EB dose and the developed resist thickness (Woo et al., 2008).

Fig. 7 shows the experiment results about the relation between electron beam dose and the developed thickness of resist, which represents that if the pattern area is different, the developed thickness of resist was also different despite the same electron beam dose. It means that the developed thickness of resist is related to the area of pattern as well as electron beam dose. Here, we could have a question. Why is the developed thickness of resist different according the pattern size despite the same electron beam dose?

Fig. 8 gives us the answer for the question. The reason for the above phenomenon can be explained by proximity effect. Because the electron beam dose is defined by the amount of exposure dose per unit area, the amount of electron beam dose is proportional to pattern area, i.e, if the pattern area is larger despite of the same electron beam dose, the pattern can be actually exposed to more amount of electron beam dose. Thus, the proximity effect such as forward and backward scattering could be strongly generated due to the increase of electron beam dose (Woo et al., 2008).

Thus, this experiment led us to two conclusions; (1) the thickness of the developed resist is proportional to electron beam dose in the identically given pattern size and (2) the thickness of the developed resist is proportional to the pattern size in the identically given electron dose.

From the Fig. 7, it was seen that the appropriate range of electron beam dose for fabricating a multi-level lens is from $55 \mu \mathrm{C} / \mathrm{cm}^{2}$ to $80 \mu \mathrm{C} / \mathrm{cm}^{2}$. To successfully fabricate a multi-level lens 


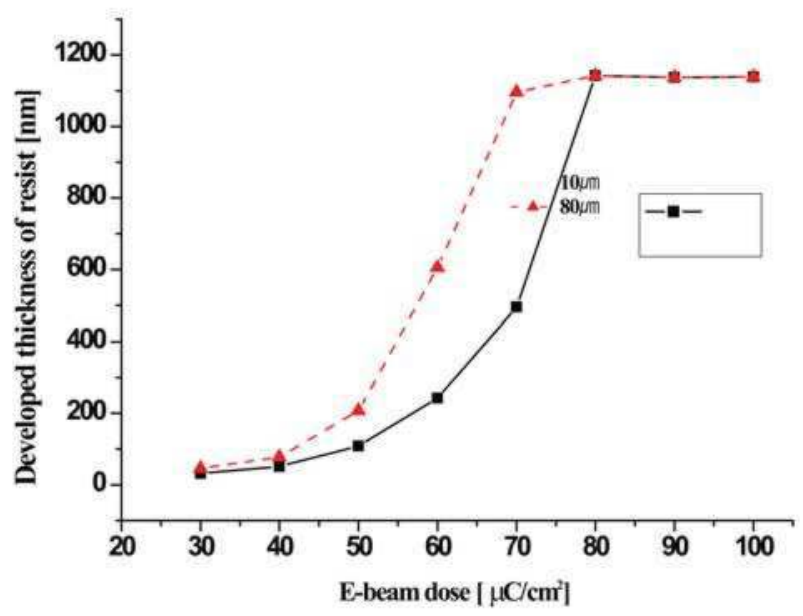

Fig. 7. The developed resist thickness with respect to exposure dose (Woo et al., 2008).
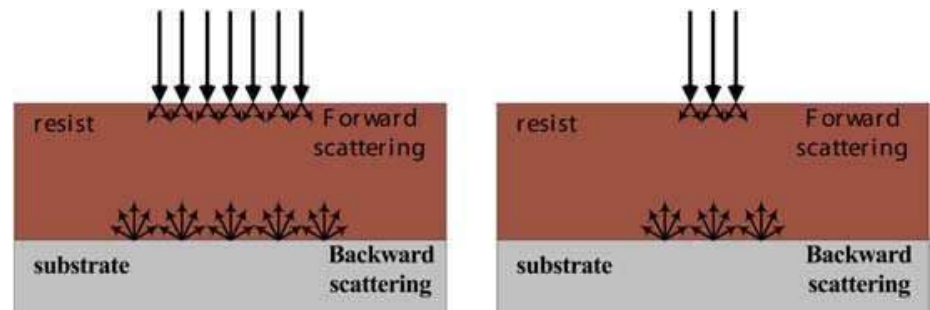

\section{Development}
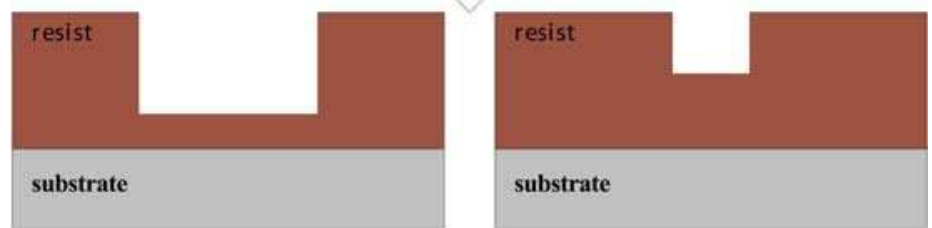

Fig. 8. Proximity effect on different pattern sizes (Woo et al., 2008).

by independent exposure method, additional experiment with an electron beam dose range from $55 \mu \mathrm{C} / \mathrm{cm}^{2}$ to $80 \mu \mathrm{C} / \mathrm{cm}^{2}$ was required with respect to a variety of pattern size. Based on a lot of experiments with this electron beam range according to the pattern width from 10 $\mu \mathrm{m}$ to $1 \mu \mathrm{m}$, it has been verified that the resist on the patterns under a width of $5 \mu \mathrm{m}$ was developed with similar thickness. Fig. 9 shows the experiment result for the relation of electron dose from $55 \mu \mathrm{C} / \mathrm{cm}^{2}$ to $80 \mu \mathrm{C} / \mathrm{cm}^{2}$ and the developed resist thickness on the pattern width of $10 \mu \mathrm{m}$. Fig. 10 shows the cross-section view of the developed resist on a pattern width of $1 \mu \mathrm{m}$. Both Fig. 9 and Fig. 10 support the independent-exposure method by which a multi-level lens can be fabricated in range of electron beam dose from $55 \mu \mathrm{C} / \mathrm{cm}^{2}$ to $80 \mu \mathrm{C} / \mathrm{cm}^{2}$. 


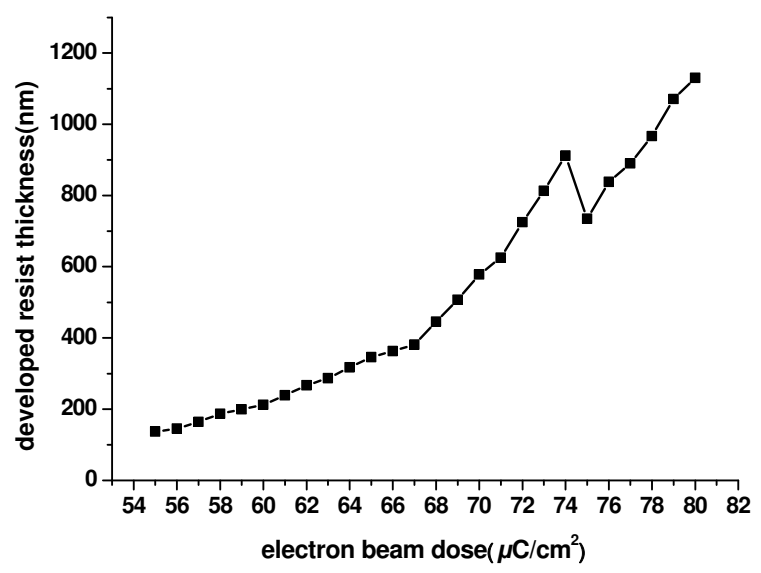

Fig. 9. The developed resist thickness with respect to electron beam dose from $55 \mu \mathrm{C} / \mathrm{cm}^{2}$ to $80 \mu \mathrm{C} / \mathrm{cm}^{2}$ on a pattern width of $10 \mu \mathrm{m}$.

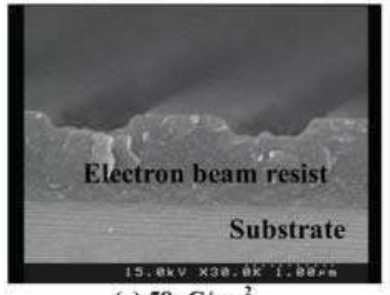

(a) $58 \mu \mathrm{C} / \mathrm{cm}^{2}$

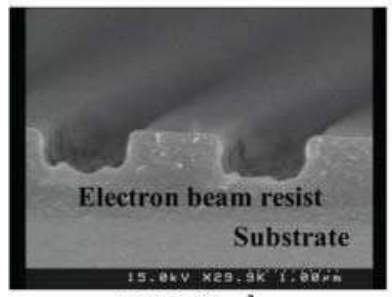

(c) $73 \mu \mathrm{C} / \mathrm{cm}^{2}$

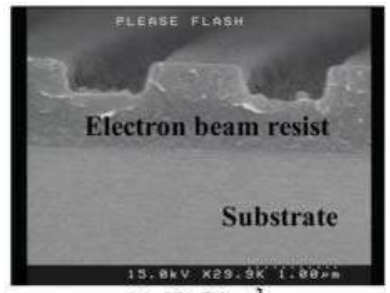

(a) $65 \mu \mathrm{C} / \mathrm{cm}^{2}$

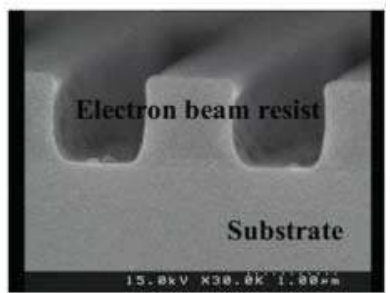

(a) $80 \mu \mathrm{C} / \mathrm{cm}^{2}$

Fig. 10. The developed resist with respect to electron beam dose on a pattern width of $1 \mu \mathrm{m}$.

\section{Fabrication of a multi-level lens using Independent-exposure method}

\subsection{Design of a multi-level lens}

Before applying the independent-exposure method to the fabrication of a multi-level lens, we should design a multi-level lens. Fig. 11 explains the multi-level lens in Fresnels zone and the relation between the radii of pattern and the focal length of the mult-level lens. A mult-level lens can be designed as stair shape in a Fresnel zone, and radii $R_{j, i}$ and thickness $d$ of a multi-level lens can be calculated geometrically using Eq. (1), 


$$
\begin{aligned}
& R_{j, i}=\sqrt{2\left(j-\frac{N-i}{N}\right) \lambda f+\left(\left(j-\frac{N-i}{N}\right) \lambda\right)^{2}} \\
& d=\frac{(N-1) \lambda}{N\left(n_{P M M A}-1\right)}
\end{aligned}
$$

where, $R_{i, j}$ is the radius of $i$ level in the $j$ th pattern and $N$-level lens, $d$ is the thickness of $N$ level lens, $\lambda$ is the wavelength and $N$ is the number of levels. (Turunen \& Wyrowski, 1997; Woo, et al., 2008).

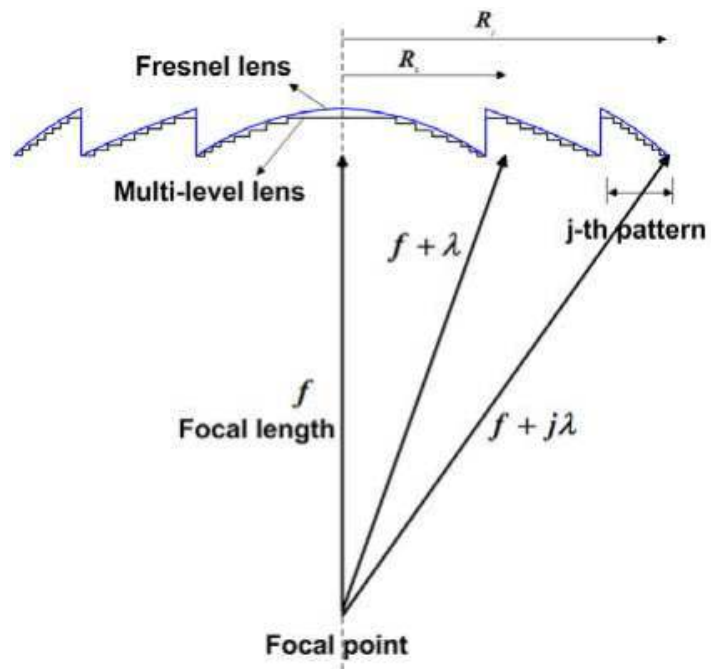

Fig. 11. A multi-level lens in Fresnel zone and relation between focal length and radii of it (Woo et al., 2009)

In this work, it is determined to fabricate a 4-level lens including a focal length of $714.5 \mu \mathrm{m}$ and a diameter of $127.4 \mu \mathrm{m}$ at the wavelength of $480 \mathrm{~nm}$. By substituting these value into Eq. (1), the the 4-level lens can be designed with a maximu pattern width of $26.204 \mu \mathrm{m}$, a minimum width of $0.966 \mu \mathrm{m}$, and a thickness of $0.723 \mu \mathrm{m}$. Depth for each level is approximately $0.241 \mu \mathrm{m}$. Fig. 12 shows the design results of the 4-level lens which has the 11 patterns.

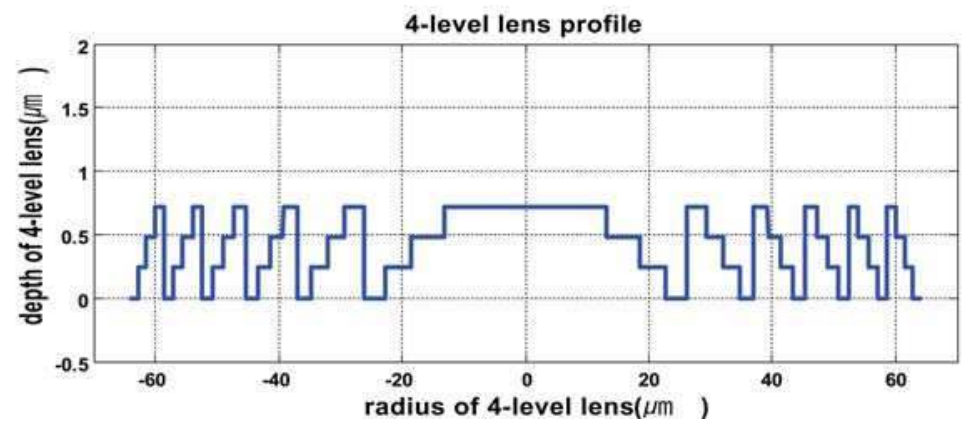

Fig. 12. The designed 4-level lens profile 
Because a mutl-level lens has a surface of stairstep, such a lens can be called a mutli-level lens or a multi-phase lens. Based on the Eq. (1) and Fig. 11, moreover, it was known that the width of lens suface at the egde of lens is smaller than that at the centre of lens.

\subsection{Fabrication process}

For the fabrication of a multi-level lens, the alignment method repeating lithography and etching process was widely used, but the independent-exposure method eliminating this repetitive process will be tried in this chapter. As early mentioned, there are two requirements in the fabrication of a multi-level lens by the independent-exposure method and $F A B$ etching with etching ration of 1:1. One is the thickness of resist should be over the thickness of the designed multi-level lens, and the other is to define the relation of electron beam and the developed resist thickness.

Fig. 13 represents the fabrication procedure of the designed 4-level lens using independentexposure lithography consisting of four main processes: (1) spin-coating, (2) electron beam lithography, (3) FAB plasma etching, and (4) hot-embossing. As shown in Fig. 13, such an independent-exposure method can contribute to a reduction of fabrication time and cost (Woo, et al, 2008).

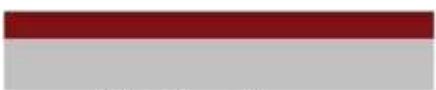

(a) spin coating

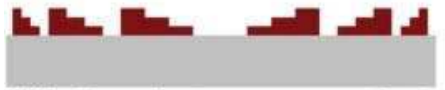

(b) Independent exposure method

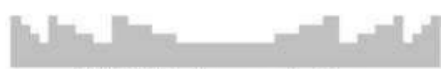

(c) FAB plasma etching

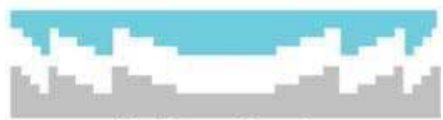

(d) Hot-embossing

Electron beam resist Silicon

PMMA

Fig. 13. The fabrication procedure of designed 4-level lens using independent-exposure method in electron beam lithography (Woo et al., 2008)

The purpose of the spin coating is to deposit electron beam resist with uniform thickness more than the designed 4-level lens.

In the electron beam lithography, the surface of resist should be made identical to that of the 4-level lens with an appropriate electron beam dose. As shown in Fig. 12, it can be easily found that the patterns in the centre of 4-level lens are much larger than those in the other side of 4-level lens. As noted earlier, the developed resist thickness can be affected by pattern size as well as by the electron beam dose, and thus appropriate electron beam dose at the centre of the 4-level lens should be considered. In order to find the appropriate electron dose for the pattern in the centre of 4-level lens, another experiment was carried out with the same pattern to that of the centre of 4-level lens shown in Fig. 14. The constant electron beam dose of $65 \mu \mathrm{C} / \mathrm{cm}^{2}$ was given to the $R_{0,2}$ pattern, the another constant electron beam dose of $58 \mu \mathrm{C} / \mathrm{cm}^{2}$ was applied on the $R_{0,3}$ pattern, and then the electron beam dose applied on the $R_{0,1}$ pattern whose width is largest in the 4-level lens was changed from $30 \mu \mathrm{C} / \mathrm{cm}^{2}$ to $65 \mu \mathrm{C} / \mathrm{cm}^{2}$. As a result of this experiment, the resist of centre pattern was completely developed with electron beam dose of $65 \mu \mathrm{C} / \mathrm{cm}^{2}$, and the appropriate electron 
dose to the $R_{0,1}$ pattern ranges from $60 \mu \mathrm{C} / \mathrm{cm}^{2}$ to $65 \mu \mathrm{C} / \mathrm{cm}^{2}$. In addition, it was found that the developed resist thickness of $R_{0,2}$ pattern given the constant electron beam dose of $65 \mu \mathrm{C} / \mathrm{cm}^{2}$ increased as the electron beam dose on the $R_{0,1}$ pattern increases. In the other words, the amount of electron beam dose can affect the adjacent pattern due to the proximity effect. Fig. 15 shows the relation between the electron beam dose and the developed resist thickness of adjacent pattern. Thus, it is also found that there is the interference of the electron beam dose between near patterns in fabrication of a multi-level lens by the independent-exposure lithography (Woo, et al., 2008).

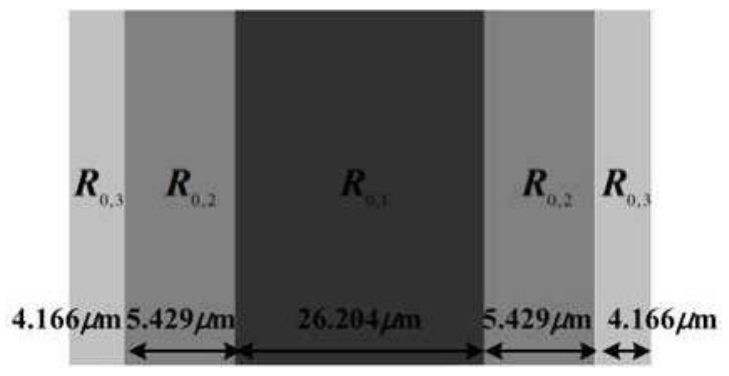

Fig. 14. Patterns with the same width to that of centre in the 4-level lens (Woo, et al., 2008)

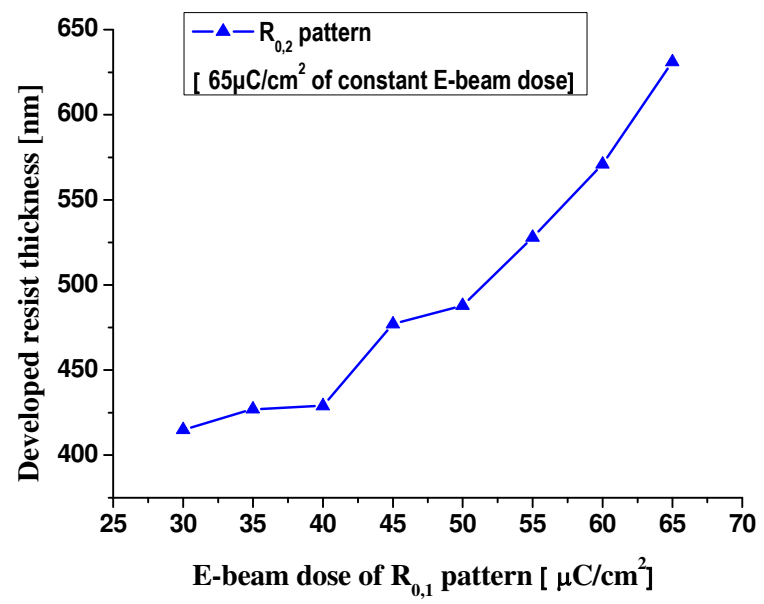

Fig. 15. Developed resist thickness of $R_{0,2}$ pattern with respect to the electron beam dose of $R_{0,1}$ pattern (Woo, et al., 2008)

Thus, there are three considerations in order to efficiently use the independent-exposure method in electron beam lithography: (1) the relation between the electron beam dose and the developed resist thickness on the same pattern, (2) the relation between the pattern size and the developed resist thickness on the same electron beam dose, (3) the interference of the electron beam dose between neighbouring patterns.

Based on these results, the designed 4-level lens was successfully fabricated by the independent exposure lithography under the conditions: $62 \mu \mathrm{C} / \mathrm{cm}^{2}$ for the 1-level step $R_{0,1}$ 
of centre pattern, $74 \mu \mathrm{C} / \mathrm{cm}^{2}$ for the 1-level step $R_{j, 1}$ of the other pattern, $68 \mu \mathrm{C} / \mathrm{cm}^{2}$ for the 2level step $R_{j, 2}$ and $58 \mu \mathrm{C} / \mathrm{cm}^{2}$ for the 3-level step $R_{j, 3}$. The $R_{0,1}$ pattern has to actually have the same thickness of resist to $R_{j, 1}$, but the reason the electron beam dose was differently given, compared to $R_{j, 1}$ pattern, is that the $R_{o, 1}$ pattern has significantly the wide width which is the largest in the 4-level lens.

After obtaining the resist whose shape is identical to the shape of the 4-level lens through the independent-exposure method, a mould of the 4-level lens can be fabricated through FAB plasma etching with 1:1 etching ratio and with the etching rate of $22 \sim 23 \mathrm{~nm} / \mathrm{min}$.

Fig. 16 shows the fabrication results for the 4-level lens by independent exposure method.
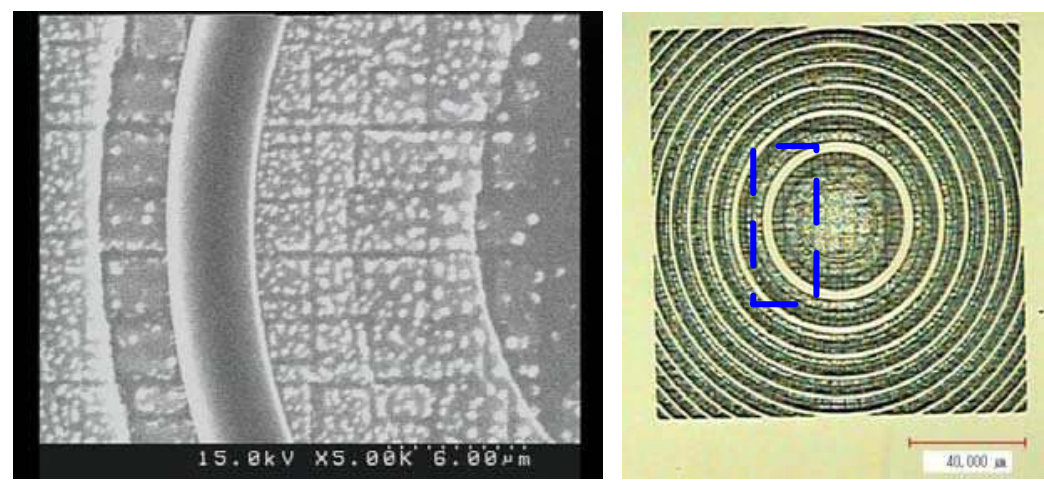

Fig. 16. The mould of 4-level lens fabricated by the independent-exposure method and FAB plasma etching (Woo, et al, 2008)

In order to obtain the 4-level lens by the fabricated mould, Hot-embossing technology with PMMA as stamp process was selected for replication. Hot embossing technology can translate the micro \& nano structure of mould into polymers with satisfaction of high accuracy and low-cost (Anke, et al., 1996; Jahns, et al., 1992).

\subsection{Fabrication results}

This chapter introduced the new fabrication method called independent-exposure method in electron beam lithography which can help significantly to reduce fabrication process. The 4-level lens designed with a maximum width of $26.204 \mu \mathrm{m}$, a minimum width of $0.966 \mu \mathrm{m}$, and a thickness of $0.723 \mu \mathrm{m}$ was successfully fabricated by the independent-exposure method which is fundamentally based on the relation among electron beam dose, pattern size and electron beam resist.

As mentioned earlier, the new method was strongly affected by the proximity effect. As shown in Fig. 16, it can be found that the surface of fabricated 4-level lens has some swellings as scattering marks owing to proximity effect.

This proximity effect has been considered as negative effect for the others process as well as independent-exposure method in the electron beam lithography. Owen introduced some interesting methods to reduce the proximity effect: (1) the precise control of the electron beam energy, (2) the calculation and pre-compensation of the energy deposition and (3) the use of multilayer resist coatings (Owen, 1990). In addition, if the resist with low sensitivity to electron beam is used, it will be also good solutions. 


\subsection{Optical evaluation}

In order to verify whether the independent-exposure method is suitable to fabricate micro optics components such as a multi-level lens and a binary structure, the optical evaluation of the fabricated 4-level lens has been performed by measuring focal length and diffraction efficiency of it.

Fig. 17 shows an overall schematic of experiment setup for the measurement of focal length and diffraction efficiency of the fabricated 4-level lens. In this evaluation, the incident light travelling to the 4-level lens has to be collimated in order to correctly measure focal length and diffraction efficiency.

For the measurement of focal length, microscope was focused on the 4-level lens, and then the stage moves vertically until the focal point of the 4-level lens clearly appears in the monitor through the microscope and CCD. This moving distance of stage is identical to focal length of the 4-level lens. As a result, the measured focal length of the 4-level lens is 712.4 $\mu \mathrm{m}$ with a depth of focus of approximately $60 \mu \mathrm{m}$, while the designed focal length of it is $714.5 \mu \mathrm{m}$. Fig. 18(a) is the measured focal point of the 4-level lens (Woo, et al., 2008).

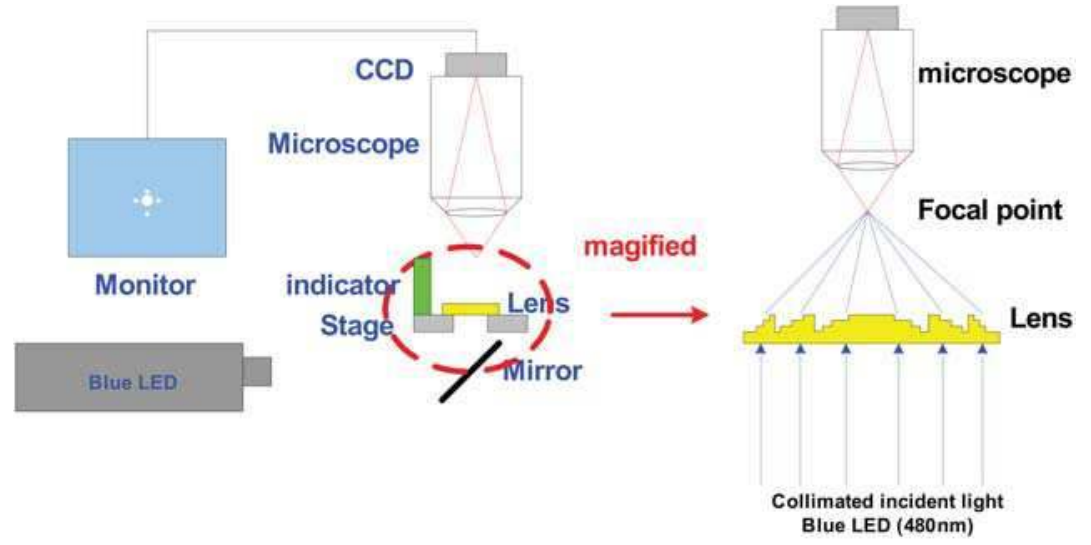

Fig. 17. Overall schematic of experiment setup for the measurement of focal length and diffraction efficiency (Woo, et al., 2008)

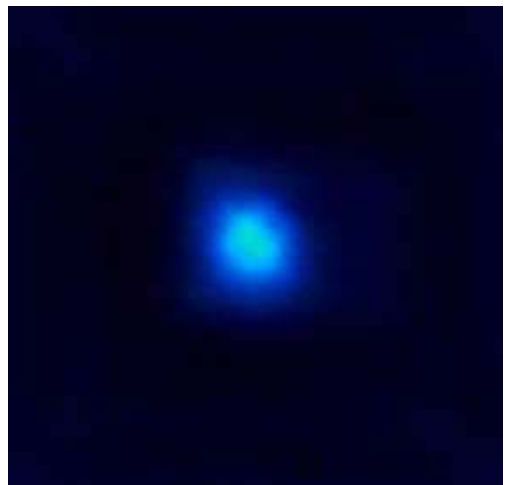

(a)

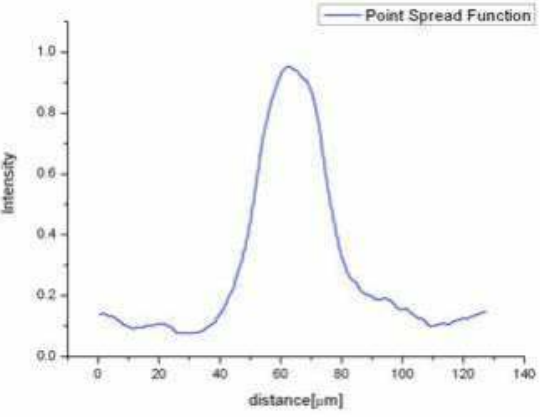

(b)

Fig. 18. Optical evaluation results: (a) the focal point of the 4-level lens, (b) point spread function of the 4-level lens (Woo et al., 2008) 
The diffraction efficiency is important factor for the evaluating diffractive optical elements such as a multi-level lens. As shown in Fig. 11, the principle of the focusing of a multi-level lens is to diffract an incident light to the focal plane of it. As the diffracted light travels to the focal plane, the diffraction efficiency can be defined as the power of diffracted light at focal point through a multi-level lens divided by the power of incident light.

Such a diffractive efficiency of a multi-level lens is dependent on the number of phase level and can be theoretically calculated by Eq. (2) (Damman, 1979; Jahns \& Walker, 1990; Woo, et al., 2008). By Eq. (2), the theoretical diffraction efficiency for a 4 -level lens is $81 \%$. From the measurement of diffraction efficiency, the real efficiency of $74.7 \%$ can be obtained. Compared to the theoretical efficiency of $81 \%$, error of diffraction efficiency results from the Fresnel reflection loss on the surface of the 4-level lens and fabrication error which includes the period and thickness error and the swelling of the 4-level lens.

$$
\eta=\left|A_{n}^{2}\right|=\operatorname{sinc}^{2}(1 / N)=\left\{\frac{\sin (\pi / N)}{\pi / N}\right\}^{2}
$$

\section{Conclusion}

In this research, the new approach called independent-exposure method in electron beam lithography for the fabrication of micro optical elements such as a multi-level lens was suggested. To sum up, this method can significantly reduce the fabrication process, i.e., a multi-level lens can be fabricated by only one process of both lithography and etching. However, before applying this method to the fabrication of a multi-level lens, proximity effect should be considered and several preliminary experiments or consideration should be required.

1. The electron beam resist should be deposited with the thickness over that of a multilevel lens.

2. The developed resist thickness is proportional to electron beam dose.

3. The developed resist increases as the pattern size increases on identically given electron beam dose.

4. There is the interference of electron beam given to adjacent patterns.

Based on the fabrication and optical results, it was evident that the independent-exposure method is suitable to fabricate a multi-level lens with non-repetitive process.

\section{Acknowledgement}

This work was conducted with the kind collaboration of the members of the Hane Laboratory in Tohoku University, and was also financially supported by the Korea Science and Engineering Foundation (KOSEF) through National Research Laboratory Program grant funded by the Korea government (MEST) (No. ROA-2008-000-20098-0)

\section{References}

Anke, I.; Kley, E.B.; Hubner, H.; Schnabel, B. \& Pohlmann, R. (1996) Replication of microoptical profiles in ORMOCER and other polymers. Proc. SPIE, Vol. 2783, pp. 325-332 
Chang, T. H. P. (1975). Proximity effect in electron-beam lithography. J. Vac. Sci, Technol.B Vol. 8, No. 6, pp. 1271-1275

Dannan, H. (1970). Blazed synthetic phase-only holograms. Optik, Vol. 31, pp.95-104

Goodman, J. and Silverstri, A. (1970). Some effects of Fourier-domain phase quantization. IBM J. Res. Dev., Vol. 14, pp.478-484

Hirai, Y.; Kikuta, H.; Okano, M.; Yotsuya, T. \& Yamamoto, K. (2000). Automatic Dose Optimization System for resist Cross-Sectional Profile in a Electron Beam Lithography, Jpn. J. Appl. Phys. Vol. 39, pp. 6831-6835

Jahns, H.; Brenner, K.H.; Daschner, W.; Doubrava, C. \& Merklein, T. (1992). Replication of dffractive micoroptical elements using PMMA moulding technique. Optik, Vol. 89, pp. $98-100$

Jahns, J \& Walker, S. J. (1990). Two-dimensional array of diffractie microlenses fabricated by thin film deposition. Appl. Opt. Vol. 29, pp. 931-936

Kley, E.B \& Schnabel, B. (1995). E-beam lithography: a suitable technology for fabrication of high-accuracy 2D and 3D surface profiles. Proc. SPIE, Vol. 2640, pp. 71-80

Kong, L.; Yi, X.; Lian, K.; \& Chen, S. (2004). Design and optical performance research of multi-phase diffractive micro lens array. J. Micromech. Micoreng, Vol. 14, pp. 11351139

Madou, M. J. (2002). Fundamentals of MICROFABRICATION, CRC PRESS, ISBN0-8493-0826-7

Owen, Geraint. (1990). Methods for proximity effect correction in electron lithography. J. Vac. Sci. Technol. B, Vol. 8, No. 6, pp. 1889-1892

Sinzinger, S. \& Jahns, J. (2003). Microoptics, WILEY-VCH, ISBN3-527-40355-8

Turunen, J. \& Wyrowski, F. (1997). Diffractive optics for industrial applications. Akademic Verlag, Berlin, ISBN3-05-501733-1

Woo, D.K.; Kane, K. \& Lee, S.K. (2008). Fabrication of a multi-level lens using independentexposure lithography and FAB plasma etching, J. Opt. A: Pure Appl. Opt, Vol. 10. No. 044001, pp. 1-6

Woo, D. K.; Hane, K.; Cho, S.C. \& Lee, S.K. (2009). Development of an integral optics system for a slim optical mouse in a slim portable electric device, J.Vac. Sci. Technol. B, Vol. 27, No. 3, pp.1422-1427

Zeon, Corporation. (2003). Technical Report ZEP520A, ZEONREX Electronic Chemicals. Ver.1.01. http://www.zeon.co.jp/ 


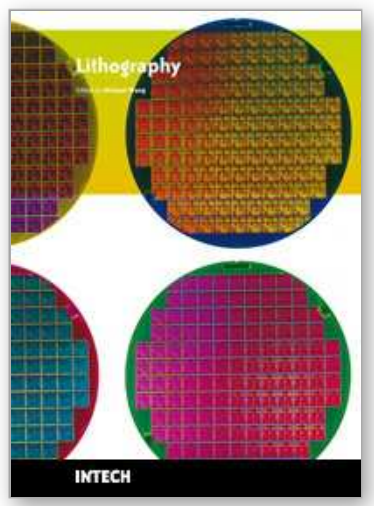

\author{
Lithography \\ Edited by Michael Wang
}

ISBN 978-953-307-064-3

Hard cover, 656 pages

Publisher InTech

Published online 01, February, 2010

Published in print edition February, 2010

Lithography, the fundamental fabrication process of semiconductor devices, plays a critical role in micro- and nano-fabrications and the revolution in high density integrated circuits. This book is the result of inspirations and contributions from many researchers worldwide. Although the inclusion of the book chapters may not be a complete representation of all lithographic arts, it does represent a good collection of contributions in this field. We hope readers will enjoy reading the book as much as we have enjoyed bringing it together. We would like to thank all contributors and authors of this book.

\title{
How to reference
}

In order to correctly reference this scholarly work, feel free to copy and paste the following:

Do-Kyun Woo and Sun-Kyu Lee (2010). Independent-Exposure Method in Electron-Beam Lithography, Lithography, Michael Wang (Ed.), ISBN: 978-953-307-064-3, InTech, Available from:

http://www.intechopen.com/books/lithography/independent-exposure-method-in-electron-beam-lithography

\section{INTECH}

open science | open minds

\section{InTech Europe}

University Campus STeP Ri

Slavka Krautzeka 83/A

51000 Rijeka, Croatia

Phone: +385 (51) 770447

Fax: +385 (51) 686166

www.intechopen.com

\section{InTech China}

Unit 405, Office Block, Hotel Equatorial Shanghai

No.65, Yan An Road (West), Shanghai, 200040, China 中国上海市延安西路65号上海国际贵都大饭店办公楼 405 单元 Phone: $+86-21-62489820$

Fax: +86-21-62489821 
(C) 2010 The Author(s). Licensee IntechOpen. This chapter is distributed under the terms of the Creative Commons Attribution-NonCommercialShareAlike-3.0 License, which permits use, distribution and reproduction for non-commercial purposes, provided the original is properly cited and derivative works building on this content are distributed under the same license. 